\title{
Historical trends of inorganic and organic fluorine in sediments of Lake Michigan
}

\author{
Garry Codling a,*, Anja Vogt ${ }^{\mathrm{a}}$, Paul D. Jones ${ }^{\mathrm{a}}$, Tieyu Wang ${ }^{\mathrm{a}, \mathrm{b}}$, Pei Wang ${ }^{\mathrm{a}, \mathrm{b}}$, Y.-L. Lu ${ }^{\mathrm{b}}$, Margaret Corcoran ${ }^{\mathrm{d}}$, \\ Solidea Bonina ${ }^{d}$, An Li ${ }^{c}$, Neil C. Sturchio ${ }^{d}$, Karl J. Rockne ${ }^{e}$, Kyunghee Ji ${ }^{a, j}$, Jong-Seong Khim ${ }^{f}$, \\ Jonathan E. Naile ${ }^{a}$, John P. Giesy ${ }^{a, f, g, h, i}$ \\ ${ }^{a}$ Toxicology Centre, University of Saskatchewan, Saskatoon, SK S7N 5B3, Canada \\ ${ }^{\mathrm{b}}$ State Key Lab of Urban and Regional Ecology, Research Center for Eco-Environmental Sciences, Chinese Academy of Sciences, Beijing 100085, China \\ ${ }^{\mathrm{c}}$ Environmental and Occupational Health Sciences, School of Public Health, University of Illinois at Chicago, 2121 West Taylor St., Chicago, IL 60612, USA \\ ${ }^{\mathrm{d}}$ Department of Earth and Environmental Sciences (MC 186), University of Illinois at Chicago, 845 W. Taylor Street, Chicago, IL 60607, USA \\ ${ }^{\mathrm{e}}$ Department of Civil and Materials Engineering (MC 246), University of Illinois at Chicago 842 West Taylor Street, Chicago, IL 60607-7023, USA \\ ${ }^{\mathrm{f}}$ Department Veterinary Biomedical Sciences, University of Saskatchewan, 44 Campus Drive, Saskatoon SK S7N 5B3, Canada \\ ${ }^{\mathrm{g}}$ Department of Biology $\mathcal{E}$ Chemistry and State Key Laboratory in Marine Pollution, City University of Hong Kong, Kowloon, Hong Kong Special Administrative Region \\ ${ }^{\mathrm{h}}$ Department of Zoology, and Center for Integrative Toxicology, Michigan State University, East Lansing, MI 48824, USA \\ ${ }^{i}$ School of Biological Sciences, University of Hong Kong, Hong Kong Special Administrative Region \\ ${ }^{j}$ School of Public Health, Seoul National University, Seoul 152-742, Republic of Korea
}

\section{H I G H L I G H T S}

- We took 8 sediment cores and 27 ponar grabs from Lake Michigan in 2010.

- Samples were extracted for total fluorine, extractable fluorine and 25 PFCs.

- PFOS and PFOA are the predominant PFCs in sediment cores.

- PFBS and PFBA are appearing in upper sections at concentrations similar to PFOS and PFOA.

- TF and EOF concentrations are orders of magnitude higher than PFCs.

\section{A R T I C L E I N F O}

\section{Article history:}

Received 14 November 2013

Received in revised form 14 March 2014

Accepted 21 March 2014

Available online 20 May 2014

Handling Editor: Gang Yu

\section{Keywords:}

Sediment

PFCs

PFOS

PFOA

Perfluorinated chemicals

Lake Michigan

\section{A B S T R A C T}

Total fluorine (TF), extractable organic fluorine (EOF) and poly- and per-fluorinated compounds (PFCs) were measured in eight dated cores of sediment taken along with 27 surface sediments from Lake Michigan in 2010. Based on rates of sedimentation, total concentrations of PFCs ( $\sum$ PFCs) reached a maximum in the later 1990s and early 2000s. This result is consistent with rapid changes in production and subsequent sedimentation. Perfluorooctanesulfonate (PFOS) and perfluorooctanoate (PFOA) are still the predominant PFCs in the cores, but in surface sediments, concentrations of perfluorobutane sulfonate (PFBS) and perfluorobutanoic acid (PFBA) are now occurring at concentrations comparable to those of PFOS and PFOA. This observation is consistent with shifts in patterns of production and use in the US and Canada. Concentrations of TF in sediments were greater than those of EOF. This result is consistent with a larger proportion of un-extractable fluorinated material in both surface sediments and in cores.

(C) 2014 Elsevier Ltd. All rights reserved.

\section{Introduction}

Per- and poly-fluorinated compounds (PFCs) are chemically and thermal stable and have the ability to lessen surface tension and

\footnotetext{
* Corresponding author. Tel.: +1 3069664978.

E-mail address: garrycodling@yahoo.co.uk (G. Codling).
}

create stable foams, which make them ideal for a range of industrial and home uses (Prevedouros et al., 2005). Though first manufactured in the late 1940 s, production of PFCs began to increase dramatically in the 1970 s with global production of perfluorosulfonate (PFOS) based compounds increasing from $\sim 500$ tonnes per annum in the 1970 s to an annual production of 4500 tonnes by the 1990s (Paul et al., 2008). 
Advances in mass spectrometry in the 1990s allowed identification and quantification of PFCs in the environment. Giesy and Kannan (2001) showed that PFC contamination in biota is a global issue, and some degradation products are toxic at environmentally relevant concentrations. This resulted in ever-increasing interest in the environmental occurrence, chemodynamics and potential effects of perfluorinated alkyl carboxylates and sulphonates (Renner, 2001). Presence of PFCs in air (Ahrens et al., 2011), water (Ahrens et al., 2010), snow (Young et al., 2007), and humans (Yeung et al., 2005) have been reported, which has improved understanding of chemical transport of PFCs. But there is limited understanding of their long-term environmental fate, although they are found to have been deposited into sediments of natural rivers, lakes and estuaries (Stock et al., 2007; Naile et al., 2010).

In Europe, North America and Japan, PSOF and its related compounds has come under restriction (USEPA, 2000; CEC, 2002). Since the production was reduced, concentrations in some environmental matrices have decreased (Kannan et al., 2005; Young et al., 2007).

Temporal trends in concentrations of PFCs have been characterized in human blood serum (Harada et al., 2007; Haug et al., 2009), biota (Holmström et al., 2004; 2010), snow (Young et al., 2007), and sediment (Stock et al., 2007; Zushi et al., 2010). In all matrices specific PFCs such as PFOA and PFOS have increased until the late 1990s. In Japan, PFCs in human blood samples from 1983-1999 on average increased by 3.5 times while in guillemot eggs from 1960 to 2003 showed a 50 fold increase (Haug et al., 2009).

This study is one of the most detailed investigations of PFCs, total fluorine (TF) and extractable organic fluorine (EOF) in the sediment of Lake Michigan. The objectives of this work were to reveal the spatial and temporal trends of PFC contamination recorded in the sediment of this freshwater lake of the North America.

\section{Methods}

\subsection{Chemicals}

Omni-Solv grade methanol (MeOH), methyl tert-butyl ether (MTBE), and sodium thiosulphate were purchased from EMD Chemicals (Gibbstown, NJ, USA), HPLC grade ammonium acetate was purchased from J.T. Baker (Phillipsburg, NJ, USA). Perfluorinated standards were purchased from Wellington Laboratories, and included 9 mass labelled recovery standards. A list of native and mass labelled PFC compounds is given in the Supporting Information along with compound name abbreviations (SI Table S1).

\subsection{Sample collection}

Both Ponar and core samplers were used during September 2010 to collect sediments from the $R / V$ Lake Guardian. See Supporting Information for detailed sampling methods (SI 1.1). The sampling locations are shown in Fig. 1, (additional location information is given in Table SI. 2).

\subsection{Sample extraction, identification and quantification of PFCS}

A total of 192 samples were analysed, including 159 core layers, 27 Ponar samples and 6 blanks, using the method described by Naile et al. (2010). Briefly Each sample was lyophilized, and homogenized, fortified with surrogate standard extracted by replicates of MTBE. Samples were cleaned using Envi Carb and reconstituted in $\mathrm{MeOH}$, before analysis by LC-MSMS (See SI 1.2 for detailed extraction method, and SI 1.3 for instrumental operating conditions). Selection of PFCs in this study was based environmental relevance and physical chemical properties that imply their potential presence in the overlying water and some propensity for particles (Ahrens et al., 2009).

\subsection{TF and EOF analysis}

Total fluorine and extractable fluorine were measured by use of combustion ion chromatography (CIC). TF was measured using a $0.01 \mathrm{~g}$ aliquot of dried sediment and EOF a fraction of the extracted sample used for PFC identification (additional detail is given in the SI 1.4).

\subsection{Rate of sedimentation}

Gamma spectroscopy using two well-type HPGe detectors yielded radioactivity profiles for ${ }^{210} \mathrm{~Pb},{ }^{241} \mathrm{Am},{ }^{226} \mathrm{Ra}$, and ${ }^{137} \mathrm{Cs}$ for all cores. Rates of sedimentation were calculated by use of methods described by Appleby (2001), and are within the range of those obtained in previous studies (Robbins and Edgington, 1975; Hermanson et al., 1991; Zhang et al., 1993). See SI 1.5 and SI Table S3 for further information.

\subsection{Quality control and assurances}

Background contamination was assessed through the use of field and travel blanks. Individual PFCs in the blanks were below the limits of detection, which were calculated as $5 \times$ the background method detection limits (MDLs) and ranged from 1 to $0.1 \mathrm{ng} \mathrm{mL}^{-1}$ (SI Table S4). Matrix spike recoveries were calculated from the mean response of the mass labelled standard, and averaged $82 \%$ for individual compounds with a range of $31-130 \%$ and low standard deviations (SI Table S4).

Statistical modelling to determine interrelationships between surface Ponar grabs $(n=27)$ using standardized squared Euclidean cluster analysis to calculate distance between samples, and clustered by nearest neighbour (single linkage) and analysis of variance (ANOVA), was performed using software Statgraphics Centurion XVI of StatPoint Technologies, Inc. (Warrenton, Virginia).

\section{Results and discussion}

Of the 25 PFCs characterized in this study, PFODA, N-MeFOSA, and N-EtFOSA were not detected in either Ponar grab samples or cores. FOSA and FOSAA were observed in $<20 \%$ of samples, at concentrations near or less than the MDL.

\subsection{PFCs in surface sediments}

Dry weight (dw) based concentrations of PFCs which were detected in $>60 \%$ of Ponar grab sediments are summarized in Table 1 . The concentrations are comparable to those previously reported from other locations in the Northern Hemisphere with the exception of Resolute Lake, Cornwallis Island Canada, where local discharge sources were suspected (Stock et al., 2007) (See SI Table S5). While not exhaustive, this comparison indicates the paucity of information on PFCs in sediments. Differences in measured concentrations among studies, especially for individual compounds, may be related to geographical locations, different methods used during sample collection, chemical analysis, and the sampling time periods. During 1997-2003, a reduction in production and use of both PFOA and PFOS as well as their precursor chemicals was implemented alongside the increased use of the 4-C PFCs (Prevedouros et al., 2005; Paul et al., 2008).

The spatial distribution of selected PFCs in surface sediments of Lake Michigan is illustrated in Fig. 2. Concentrations of $\sum_{25} \mathrm{PFCs}$ 


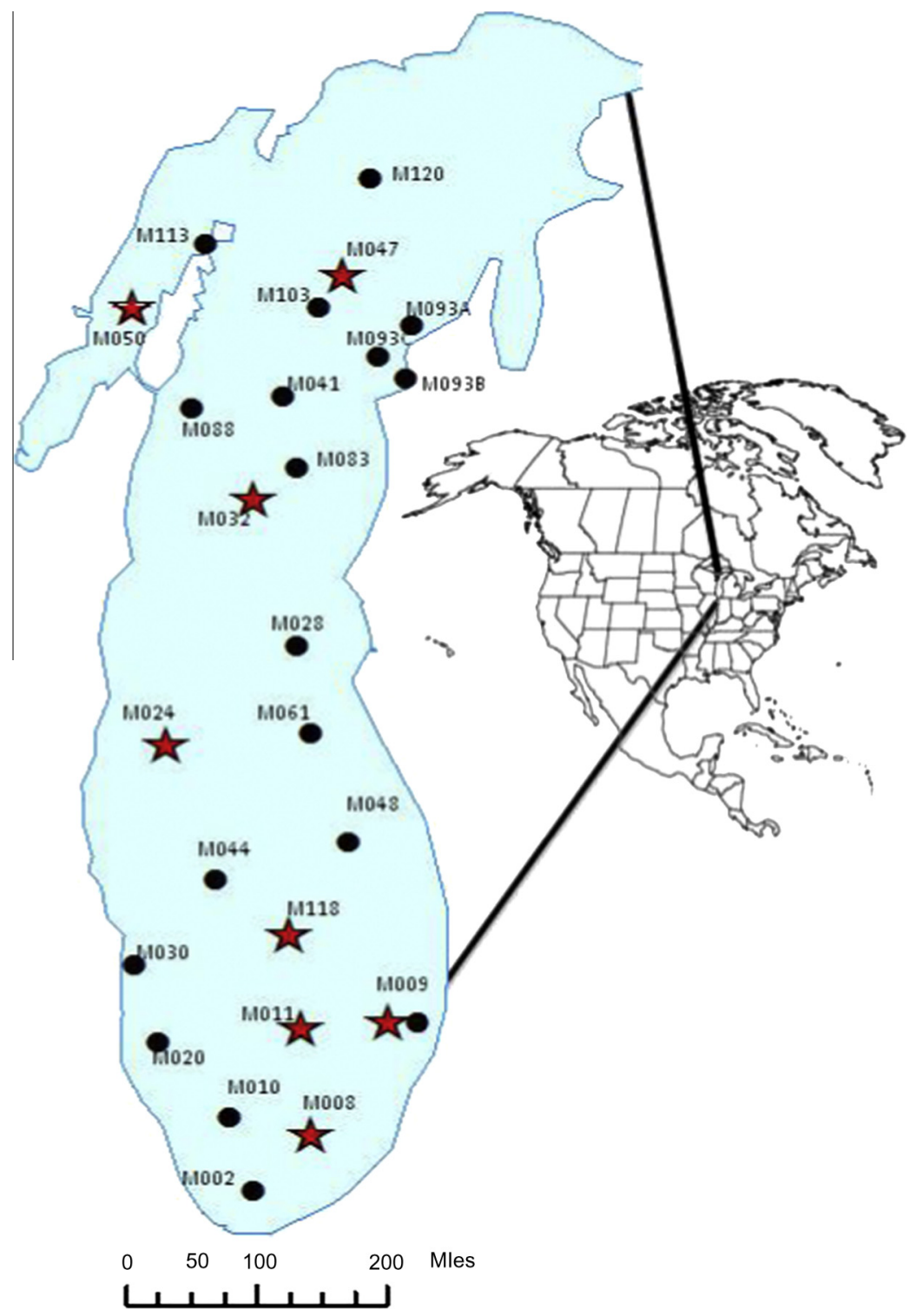

Fig. 1. Sampling locations in Lake Michigan. Stars represent locations where both Ponar grab and core were taken, while circles indicate Ponar samples only.

Table 1

Mean concentrations of PFC, extractable organic fluorine (EOF) and total fluorine (TF) in sediments of Lake Michigan from 1900 to 2010 sediment cores and surface Ponar samples, the 48 core sections represent all sections from 1900 to 2010.

\begin{tabular}{lcccc}
\hline Compound & \multicolumn{2}{l}{ Ponar-surface samples $(n=27)$} & \multicolumn{2}{c}{ Sediment cores $(n=48)$} \\
\hline$n g g^{-1}(d w)$ & & & & \\
PFBA & 0.57 & (n.d.-0.97) & 0.37 & (n.d.-1.32) \\
PFPeA & 0.17 & (n.d.-1.30) & 0.15 & (n.d.-0.82) \\
PFOA & 0.21 & (n.d.-0.42) & 0.75 & (n.d.-3.66) \\
PFTeDA & 0.05 & (n.d.-0.15) & 0.14 & (n.d.-0.29) \\
PFBS & 0.19 & (n.d.-0.52) & 0.52 & (n.d.-7.93) \\
PFOS & 0.45 & (n.d.-1.15) & 2.70 & (n.d.-12.78) \\
FOSA & 0.05 & (n.d.-0.083) & 0.48 & (n.d.-0.78) \\
N-MeFOSE & 0.30 & (n.d.-0.93) & 0.29 & (n.d.-0.98) \\
N-EtFOSE & 0.23 & $(0.06-0.45)$ & 0.26 & (n.d.-0.86) \\
$\sum{ }_{25}$ PFC & 2.33 & $(0.89-4.94)$ & 4.4 & $(0.4-24.1)$ \\
$m g g^{-1}(d w)$ & & & & \\
EOF & 1.60 & $(0.6-4.8)$ & 2.16 & $(0.8-4.8)$ \\
TF & 571 & $(96-1181)$ & 782 & $(375-1322)$ \\
\hline
\end{tabular}

were greater at northern (M120, M050 and M103) and southern (M002, M010) regions compared with locations in the centre of the lake. The distribution of the 8 most commonly detected compounds (PFBS, PFPeA, PFTeDA, PFOS, PFBA, PFOA, N-MeFOSE and N-EtFOSE) differed at the two ends of the lake. The major feature of water currents within Lake Michigan is a southern gyre and a northern gyre creating two basins and limited mixing on the east coast. This is somewhat reflected in the observed spatial pattern of PFCs. The southern Great Lakes region has a high population density with an estimated 5.5 million people and heavy industry, compared to $\sim 1$ million in the northern region. Studies have indicated that some atmospheric contaminants across Lake Michigan may be traced to the sources in the southern region (Gratz et al., 2013). Concentrations of PFOS and N-EtFOSE were greatest in sediments from the northern portion of Lake Michigan. Biotransformation of $\mathrm{N}$-EtFOSE results in PFOS as one of the terminal products, it might be considered that they come from the same source, though no significant correlation was observed (Rhoads et al., 2008). N-EtFOSAA, though not among the 10 PFCs with the greatest concentration/ detection, was observed most frequently in sediments in the northern basin, this has been linked to a degradation pathway of $\mathrm{N}$ EtFOSE.

In Lake Michigan, PFOA and PFOS were among the predominant PFCs in most samples. PFBA was found in $21 / 27$ grab samples at a 

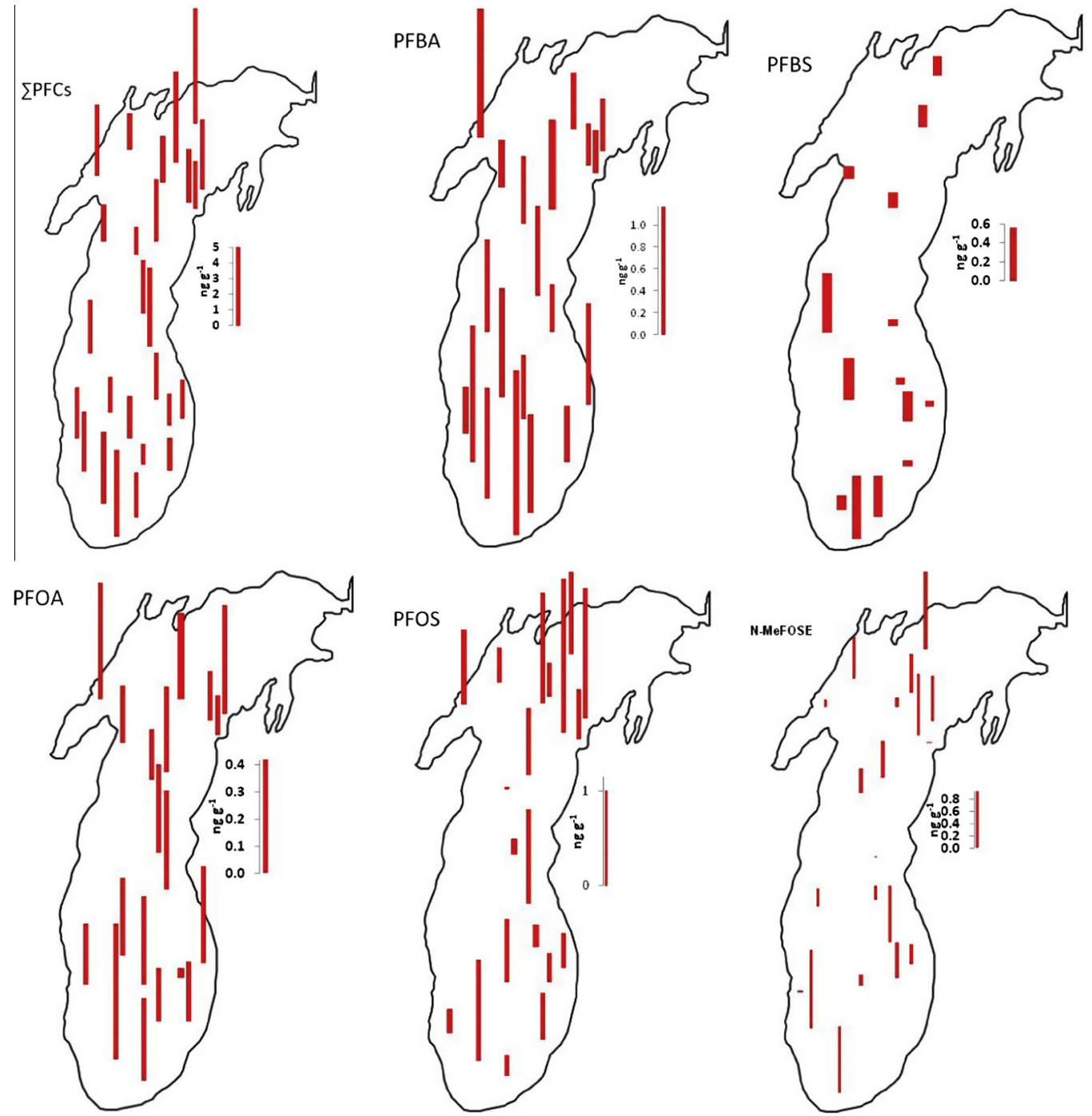

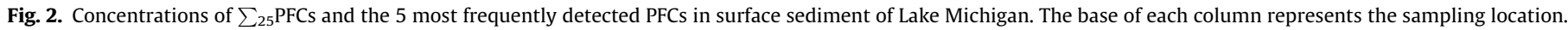

mean concentration of $0.57 \mathrm{ng} \mathrm{g}^{-1}$, similar to the mean concentration of PFOS $\left(0.44 \mathrm{ng} \mathrm{g}^{-1}\right)$. This result differs from those of previous studies (e.g. Stock et al., 2007; Zushi et al., 2010), where PFBA was often not noted. However, since PFBS and PFBA have been used as substitutes for C-8 PFCs, their production has increased during the last decade. Studies have found PFBA, and PFBS in the waters of North Sea, North Bohai Sea, and the River Rhine in Germany; at some locations C-4 PFCs are now predominant (Ahrens et al., 2009; Möller et al., 2010; Wang et al., 2012).

PFBA and PFBS had greater concentrations than PFOS or PFOA in sediments from the southern region of Lake Michigan. For instance, at M002 the concentration of PFBA was $1.2 \mathrm{ng} \mathrm{g}^{-1} \mathrm{dw}$, but that of PFOS was $<$ LOQ. Location M010, which is located further south, exhibited the greatest concentration of PFOA $\left(0.42 \mathrm{ng} \mathrm{g}^{-1} \mathrm{dw}\right)$ and one of the greatest concentrations of PFOS $\left(0.76 \mathrm{ng} \mathrm{g}^{-1} \mathrm{dw}\right)$.

Cluster analysis for PFBS, PFPeA, PFTeDA, PFOS, PFBA, PFOA, NMeFOSE, and N-EtFOSE (SI Fig. S1) indicate site M002 close to Chicago and M030 near Milwaukee both appear different than all other sample sites. Site M020 between Chicago and Milwaukee also differs somewhat from other sites though not as strongly. The remaining Ponar grab sites are set into 3 distinct groups. Sites in deep water of the north and south basin are similar, such as M009, M010 in the south and M032 and M041 in the north, in keeping with predictions for contaminant movement (Robbins and Edgington, 1975). The other two groups appear at intermediate and shallower depths closer to the shoreline though there is no significant separation, i.e., not all close to shore in shallow water are similar nor are the intermediate depths. There were no significant correlations between PFC concentrations in sediments and the depth of overlying water. A weak correlation between concentrations of TF and depth was observed, but this association was not statistically significant $(P>0.05)$.

\subsection{PFCs in sediment cores}

Depending on the location each core represents between 150 and 1200 years of sedimentation. A $1 \mathrm{~cm}$ upper sediment layer presents from $\sim 4$ years to $\sim 20$ years, with compaction of deeper sediment resulting in a core section covering a greater period. Differences in sedimentation rate result in different temporal resolution of layers among cores. Because the use of fluorinated compounds, such as additives to drinking water, began prior to the mass production of PFCs began in the 1940s, a 100 year period was examined. Through dating cores M008 and M032 indicate missing the upper 16 and 13 years respectively. While there can be downward diffusion of organic compounds, detectable concen- 
trations of PFCs observed deeper than the year 1900 is likely due to bioturbation, or pore water movement (Ahrens et al., 2009).

Concentrations of $\sum_{10}$ PFCs (PFBA, PFOA, PFNA, PFBS, PFHxS, PFOS, PFDS, N-MeFOSE, N-EtFOSE and N-EtFOSAA) ranged from $10 \pm 3.9 \mathrm{ng} \mathrm{g}^{-1} \mathrm{dw}$ in layers within cores dated at approximately 2000 to $2.1 \pm 0.9 \mathrm{ng} \mathrm{g}^{-1} \mathrm{dw}$ in those from 1900 to 1910 . The general exponential increase in concentrations of PFC from deeper sediment to layers approximating to the 1990s is consistent with known history of production and use of PFCs in the U.S. and Canada (Paul et al., 2008; SI Fig. S2). This is due primarily to the increases in PFOS, PFOA, and PFHxA, (Fig. 3 and SI Fig. S3).

Location M018 and to a lesser extent locations M032, M011 and M009 all contained measureable concentrations of a range of PFCs in the 1920s and early 1930s. Even when greater concentrations of PFBS at location M018 were eliminated, the concentration of $\sum_{10-}$ PFCs was greater in this decade than those in sediments deposited between 1900-1920 and 1930-1940. The cause of this is unknown, though industry at the time was not actively creating PFCs, some might have been by-products of industrialization.

Locations M008, M024, M009 and M047 exhibited an increase in concentration of $\sum_{10} \mathrm{PFCs}$ in the late 1950 s, compared to concentrations measured prior to and just after that time. Mostly this was due to greater concentrations of PFOA. Since this pattern was observed in multiple samples from the southern region of Lake Michigan, and in the region of deposition predicted due to the north basin gyre, it might be evidence of initial larger-scale manufacture of PFCs prior to improved waste treatment that began to be implemented in the 1960s and was reflected in the decrease of detectable concentrations observed in the subsequently deposited core sections. Another factor might be that in 1958 one of the largest storms with winds in excess of $100 \mathrm{~km} \mathrm{~h}^{-1}$ resulted in mixing of sediments and additional runoff (Hermanson et al., 1991). The 1958 storm differed from subsequent large storms on Lake Michigan, because the wind was predominantly from the southwest, while wind in later storms was from the north or northeast (NOAA, 2010).

Location M050, situated within Green Bay, exhibited lesser concentrations of PFCs in both surface samples and cores, and thus dif- fered from the rest of Lake Michigan. Sedimentation rate at this location was high $\sim 4$ year $\mathrm{cm}^{-1}$, but M009 had 3 times greater sedimentation than M050, but shows concentrations similar to the rest of the lake. Concentrations of N-EtFOSAA were greater than those of other PFCs, with a peak concentration of $4.4 \mathrm{ng} \mathrm{g}^{-1}$ in the core section dated at $\sim 1980$. N-EtFOSAA is a degradation product of N-EtFOSE, Historically, Green Bay has had paper mills that might have used N-EtFOSE attached to a phosphate ester in protective paper coatings. Due to the volatility of this compound, it is likely to have entered the atmosphere during production or use and thus been subject to photo-degradation to terminal products like PFOS at locations remote from sources (Martin et al., 2004). The greater concentrations of N-EtFOSAA at M050 might be indicative of treated wastewater being a significant source. In activated sludge of sewage treatment plants, N-EtFOSE was detected (3M, 2000). A proposed scheme for biotransformation of $\mathrm{N}$-EtFOSE in activated sludge process is that N-EtFOSAA is a major degradation product with a proportion not degraded further towards a terminal product like PFOS and remained as N-EtFOSAA (Rhoads et al., 2008). Our measurements at M050 are consistent with this hypothesis.

Previously published estimates of global production of perfluorooctane sulfonyl fluoride from 1970 to 2005 are closely related to observed trends in sediment contamination (Prevedouros et al., 2005; Paul et al., 2008). This is also consistent with the expectation that much of the PFOS was released during production, rather than through use, and that there is a rapid environmental turnover from release to sedimentation. Additional measurements in the future are needed to confirm if the decrease observed from the late 1990s in the majority of cores is statistically significant.

\subsection{TF and EOF}

Mean concentrations of total fluorine (TF) and extractable organic fluorine (EOF) are summarized (Table 1). In this study the proportion of TF represented by EOF was $\sim 0.30 \%$ and $\sim 0.44 \%$ in sediment cores and Ponar grabs, respectively. The mass of unquantified organic fluorine is not unique; a study of surface water
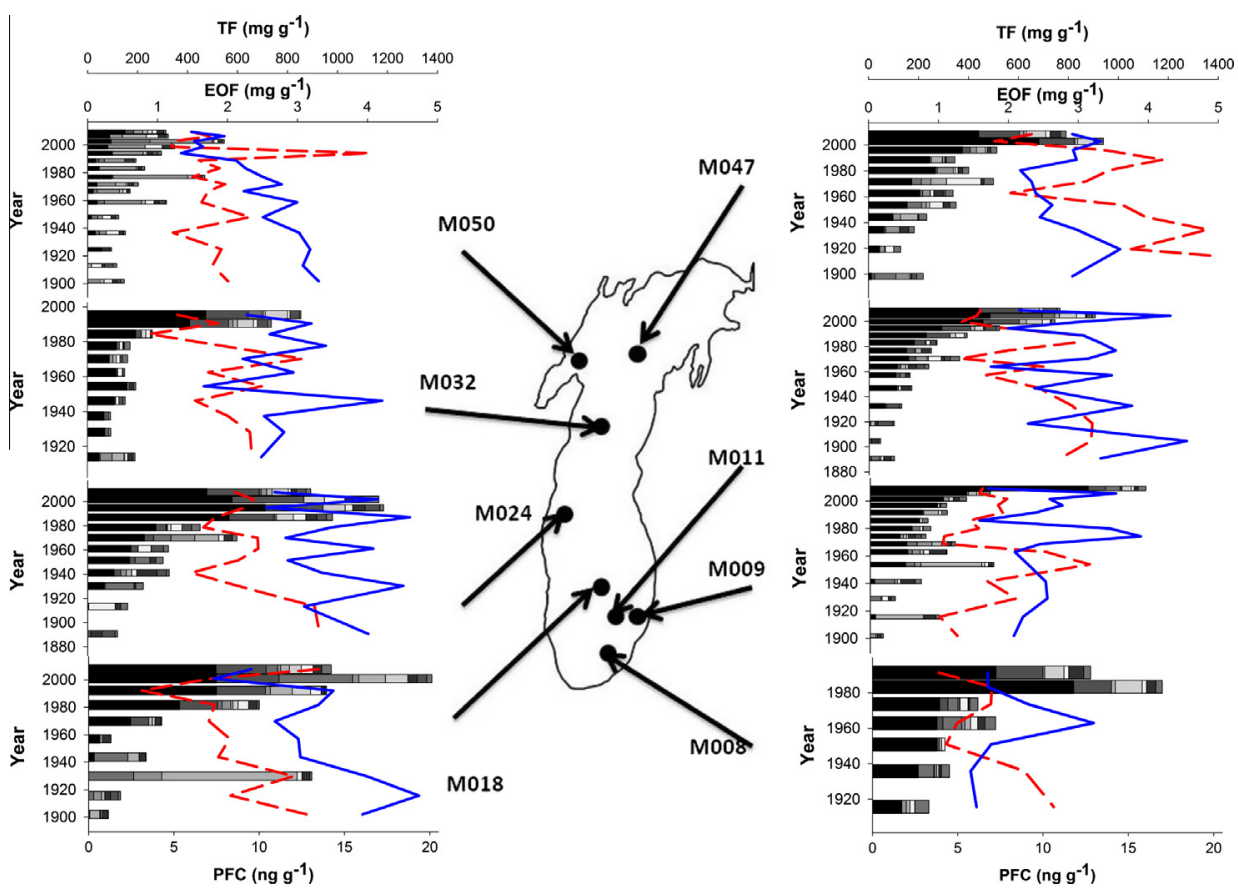

Fig. 3. Concentration versus core depth of $\sum_{10} \mathrm{PFCs}$ (bars), TF (dotted lines) and EOF (solid lines). The bars include the 10 most frequently detected individual PFCs. 
after a spill of fire retardant showed that the total mass of PFCs identified was significantly less than that the ${ }^{19} \mathrm{~F}$ measured by NMR (Moody et al., 2001). There are other instances where for non-biological matrices EOF has occurred in significantly greater abundance than that identified by the commonly described PFCs (Trojanowicz et al., 2011). In comparison, EOF was 63\% $(n=10)$ and $38 \%(n=10)$ of TF, respectively, for two cetacean species (Yeung et al., 2009). Ponar samples contained, on average, greater concentrations of TF within the central basins of Lake Michigan (Fig. SI 4). This result is consistent with predictions that sediment is deposited towards the central gyre (Robbins and Edgington, 1975). Concentrations of EOF across the southern basin were similar, though with a slight elevation on the eastern side in keeping with water flow. Greatest concentrations of EOF were observed at site $M 093_{(b, c)}$, in the northern basin collected near to a river input. M093 sites also had the greatest concentrations of PFOS within the northern basin (Fig. 2).

In this study, elemental fluorine accounted for by quantified PFCs represented $0.16 \%$ and $0.09 \%$ of EOF in sediment cores and Ponar samples, respectively. In contrast, molar concentrations of F accounted for $24 \%$ and $22 \%$ of the EOF for Indo-pacific humpback dolphin and finless porpoise, respectively (Yeung et al., 2009). For human blood serum in the US and Japan, Miyake et al. (2007) was able to determine all but $20 \%$ of the EOF as being PFCs. In a study in China, unknown EOF material accounted for $30 \%$ of the EOF in samples from cities of Beijing, Shenyang, and Guiyang, while it was 70\% in Jintan (Yeung et al., 2008).

Concentrations of TF in cores from some locations, such as M041 and M024, indicate limited changes over the last 100 years, though fluctuations and low resolution make trends difficult to interpret. There is some evidence of a decrease in TF within cores from locations M050, M008 and M018 during the last 20 years (Fig. 3), and this may be indicative of the improved water quality after the 1978 Great Lakes Water Quality Agreement that created a zero discharge policy.

At some locations, there appeared to be a relationship between concentrations of TF and EOF, such that peaks of TF and EOF both increased. A lag was observed at some locations such as M009 and M008 both of which have greater sedimentation rates and hence greater resolution of their chronological profiles. The significance of this might be that some forms of non-extractable fluorine could be converted to an EOF form over a period in sediment, though further analysis is needed to identify unknown compounds.

\section{Acknowledgements}

This research was part of the Great Lakes Sediment Surveillance Program (GLSSP), which is supported by a Cooperative Agreement from the U.S. EPA Great Lakes Restoration Initiative with Assistance No. GL-00E00538 (EPA Program Officer Todd Nettesheim). The research was also supported, in part, by a Discovery Grant from the Natural Science and Engineering Research Council of Canada (Project \# 326415-07) and a grant from the Western Economic Diversification Canada (Project \# 6578 and 6807). The authors wish to acknowledge the support of an instrumentation grant from the Canada Foundation for Infrastructure. We thank the Captain and crew of the R/V Lake Guardian for the assistance in sampling.

\section{Appendix A. Supplementary material}

Supplementary data associated with this article can be found, in the online version, at http://dx.doi.org/10.1016/j.chemosphere. 2014.03.080.

\section{References}

3M, 2000. POSF Life Cycle Waste Stream Estimates. AR226-0681, pp. 1063-1072.

Ahrens, L., Gerwinski, W., Theobald, N., Ebinghaus, R., 2010. Sources of polyfluoroalkyl compounds in the North Sea, Baltic Sea and Norwegian Sea: Evidence from their spatial distribution in surface water. Mar. Pollut. Bull. 60, 255-260.

Ahrens, L., Shoeib, M., Del Vento, S., Codling, G., Halsall, C., 2011. Polyfluoroalkyl compounds in the Canadian Arctic atmosphere. Environ. Chem. 8, 399-406.

Ahrens, L., Yamashita, N., Yeung, L.W.Y., Taniyasu, S., Horii, Y., Lam, P.K.S., Ebinghaus, R., 2009. Partitioning Behaviour of Per- and Polyfluoroalkyl Compounds between Pore Water and Sediment in Two Sediment Cores from Tokyo Bay, Japan. Environ. Sci. Technol. 43, 6969-6975.

Appleby, P.G., 2001. Tracking Environmental Change Using Lake Sediments. In: Last, W.M., Smol, J.P. (Eds.), Chronostratigraphic techniques in recent sediments. Kluwer Academic Publishers, Dordrecht, The Netherlands, pp. 171-203.

CEC, 2002. Commission Decision 2002/657/EC implementing council directive 96/ 23/EC concerning the performance of analytical methods and the interpretation of results. J. Euro. Union L221, 08-36.

Giesy, J.P., Kannan, K., 2001. Global distribution of perfluorooctane sulfonate in wildlife. Environ. Sci. Technol. 35, 1339-1342.

Gratz, L.E., Keeler, G.J., Marsik, F.J., Barres, J.A., Dvonch, J.T., 2013. Atmospheric transport of speciated mercury across southern Lake Michigan: Influence from emission sources in the Chicago/Gary urban area. Sci. Total Environ. 448, 84-95.

Harada, K., Koizumi, A., Saito, N., Inoue, K., Yoshinaga, T., Date, C., Fujii, S., Hachiya N., Hirosawa, I., Koda, S., Kusaka, Y., Murata, K., Omae, K., Shimbo, S., Takenaka, K., Takeshita, T., Todoriki, H., Wada, Y., Watanabe, T., Ikeda, M., 2007. Historical and geographical aspects of the increasing perfluorooctanoate and perfluorooctane sulfonate contamination in human serum in Japan. Chemosphere 66, 293-301.

Haug, L.S., Thomsen, C., Becher, G., 2009. Time Trends and the Influence of Age and Gender on Serum Concentrations of Perfluorinated Compounds in Archived Human Samples. Environ. Sci. Technol. 43, 2131-2136.

Hermanson, M.H., Christensen, E.R., Buser, D.J., Chen, L.-M., 1991. Polychlorinated biphenyls in dated sediment cores from green Bay and Lake Michigan. J. Great Lakes Res. 17, 94-108.

Holmström, K.E., Järnberg, U., Bignert, A., 2004. Temporal Trends of PFOS and PFOA in Guillemot Eggs from the Baltic Sea, 1968-2003. Environ. Sci. Technol. 39, 8084.

Kannan, K., Yun, S.H., Evans, T.J., 2005. Chlorinated, brominated, and perfluorinated contaminants in livers of polar bears from Alaska. Environ. Sci. Technol. 39, 9057-9063.

Martin, J.W., Kannan, K., Berger, U., DeVoogt, P., Fields, J., Franklin, J., Giesy, J.P., Harner, T., Muir, D., Scott, B., Kaiser, M., Järnberg, U., Jones, K.C., Mabury, S.A. Schroeder, H., Simcik, M., Sottani, C., Bavel, B.V., Kärrman, A., Lindström, G. Leeuwen, S.V., 2004. Researchers push for progress in perfluoralkyl analysis. Environ. Sci. Technol. 38, 249A-255A.

Miyake, Y., Yamashita, N., So, M.K., Rostkowski, P., Taniyasu, S., Lam, P.K.S., Kannan, K., 2007. Trace analysis of total fluorine in human blood using combustion ion chromatography for fluorine: A mass balance approach for the determination of known and unknown organofluorine compounds. J. of Chrom. A 1154, 214-221.

Möller, A., Ahrens, L., Surm, R., Westerveld, J., van der Wielen, F., Ebinghaus, R., de Voogt, P., 2010. Distribution and sources of polyfluoroalkyl substances (PFAS) in the River Rhine watershed. Environ. Pollut. 158, 3243-3250.

Naile, J.E., Khim, J.S., Wang, T., Chen, C., Luo, W., Kwon, B.-O., Park, J., Koh, C.-H., Jones, P.D., Lu, Y., Giesy, J.P., 2010. Perfluorinated compounds in water, sediment, soil and biota from estuarine and coastal areas of Korea. Environ. Pollut. 158, 1237-1244.

Paul, A.G., Jones, K.C., Sweetman, A.J., 2008. A first global production, emission, and environmental inventory for perfluorooctane sulfonate. Environ. Sci. Technol. 43, 386-392.

Prevedouros, K., Cousins, I.T., Buck, R.C., Korzeniowski, S.H., 2005. Sources, fate and transport of perfluorocarboxylates. Environ. Sci. Technol. 40, 32-44.

Renner, R., 2001. Growing Concern Over Perfluorinated Chemicals. Environ. Sci. Technol. 35, 154A-160A.

Rhoads, K.R., Janssen, E.M.L., Luthy, R.G., Criddle, C.S., 2008. Aerobic Biotransformation and Fate of N-Ethyl Perfluorooctane Sulfonamidoethanol (N-EtFOSE) in Activated Sludge. Environ. Sci. Technol. 42, 2873-2878.

Robbins, J.A., Edgington, D.N., 1975. Determination of recent sedimentation rates in Lake Michigan using Pb-210 and Cs-137. Geoch et Cosmo Acta 39, 285-304.

Stock, N.L., Furdui, V.I., Muir, D.C.G., Mabury, S.A., 2007. Perfluoroalkyl contaminants in the canadian arctic: evidence of atmospheric transport and local contamination. Environ. Sci. Technol. 41, 3529-3536.

Trojanowicz, M., Musijowski, J., Koc, M., Donten, M.A., 2011. Determination of Total Organic Fluorine (TOF) in environmental samples using flow-injection and chromatographic methods. Anal. Methods 3, 1039-1045.

USEPA, 2000. Perfluorooctyl Sulfonates; Proposed Significant New Use Rule. U.S. Environmental Protection Agency, pp. 62319-62333.

Wang, T., Khim, J.-S., Chen, C., Naile, J.E., Lu, Y.-L., Kannan, K., Park, J.-S., Giesy, J.P. 2012. Perfluorinated compounds in surface waters from northern china: comparison to level of industrialization. Environ. Int. 42, 37-46.

Yeung, L.W.Y., Miyake, Y., Taniyasu, S., Wang, Y., Yu, H., So, M.K., Jiang, G., Wu, Y., Li, J., Giesy, J.P., Yamashita, N., Lam, P.K.S., 2008. Perfluorinated Compounds and Total and Extractable Organic Fluorine in Human Blood Samples from China. Environ. Sci. Technol. 42, 8140-8145. 
Yeung, L.W.Y., Miyake, Y., Wang, Y., Taniyasu, S., Yamashita, N., Lam, P.K.S., 2009. Total fluorine, extractable organic fluorine, perfluorooctane sulfonate and other related fluorochemicals in liver of Indo-Pacific humpback dolphins (Sousa chinensis) and finless porpoises (Neophocaena phocaenoides) from South China. Environ. Pollut. 157, 17-23.

Yeung, L.W.Y., So, M.K., Jiang, G., Taniyasu, S., Yamashita, N., Song, M., Wu, Y., Li, J. Giesy, J.P., Guruge, K.S., Lam, P.K.S., 2005. Perfluorooctanesulfonate and related fluorochemicals in human blood samples from China. Environ. Sci. Technol. 40 $715-720$.
Young, C.J., Furdui, V.I., Franklin, J., Koerner, R.M., Muir, D.C.G., Mabury, S.A., 2007. Perfluorinated acids in arctic snow: new evidence for atmospheric formation. Environ.Sci. Technol. 41, 3455-3461.

Zhang, X., Christensen, E.R., Yan, L.-Y., 1993. Fluxes of Polycyclic Aromatic Hydrocarbons to Green Bay and Lake Michigan Sediments. J. Great Lakes Res. 19, 429-444.

Zushi, Y., Tamada, M., Kanai, Y., Masunaga, S., 2010. Time trends of perfluorinated compounds from the sediment core of Tokyo Bay, Japan (1950s-2004). Environ. Pollut. 158, 756-763. 